\title{
Borohydrido rare earth complexes as precatalysts for the polymerisation of styrene
}

\author{
Philippe Zinck, Marc Visseaux*, André Mortreux \\ Unité de Catalyse et Chimie du Solide, UMR 8181, Cité Scientifique, Villeneuve d'Ascq, France
}

This contribution is dedicated to Glen Deacon, on the occasion of his $70^{\text {th }}$ birthday

Keywords: Catalysis, lanthanides, borohydrides, alkylmagnesium, styrene, polymerisation

\begin{abstract}
Borohydrido based lanthanide complexes associated with $n$-butylethylmagnesium are efficient catalytic systems for the polymerisation of styrene. The reaction is quantitative at $50^{\circ} \mathrm{C}$ after several hours. Two growing chains per magnesium atom can be evidenced, and chain transfer between the lanthanide and the magnesium atoms may occur. The activity of such catalytic systems is found to be related to the nature of the rare earth.
\end{abstract}


Polymers and copolymers exhibiting an architecture that can be fine-tuned up to the level of a single molecule present potentialities in many fields of applications. The design of highly versatile catalytic systems affording architecture controlled (co-)polymerisations is thus of great interest. In that context, lanthanides chlorides and borohydrides associated to alkylmagnesiums are known as efficient systems for living and stereoselective polymerisations as outlined hereafter where $\mathrm{X}$ represents $\mathrm{Cl}, \mathrm{BH}_{4}$ or $\mathrm{OR}$ and $\mathrm{M}$ ethylene or conjugated dienes :

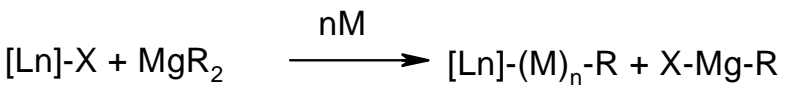

The living polymerisation of ethylene has been reported using chlorolanthanocene combined to alkylmagnesium, and the resulting long chain dialkylmagnesiums could further be used for a block copolymerisation with methylmethacrylate and $\varepsilon$-caprolactone [1]. Neodymium alkoxides associated with dialkylmagnesiums have also been shown to lead to living polymerisation of ethylene and butadiene [2]. More recently, neodymium borohydrides have been reported to afford living transfer polymerisation of ethylene [3] as well as highly trans-stereospecific and well controlled polymerisation of isoprene [4-5]. We have explored in this frame the polymerisation of styrene with borohydrido rare earth complexes associated to $n$-butylethylmagnesium.

Significative entries are reported Table 1. Using $\mathrm{Nd}\left(\mathrm{BH}_{4}\right)_{3}(\mathrm{THF})_{3}(\mathbf{1})$ as the precatalyst, the reaction is found to be quantitative after several hours at $50^{\circ} \mathrm{C}$ (entry 2). The number-average molecular weight of the resulting polymer is consistent with the growth of two macromolecular chains per magnesium atom, and the system is characterized by an apparent first-order kinetic plot (Fig. 1). If the polydispersity index increases along the polymerisation performed with a $\mathrm{Mg} / \mathrm{Nd}$ ratio of 1 (entries1-2), a large excess of dialkylmagnesium affords a well controlled oligomerisation, as illustrated entry 3. The occurrence of chain transfer reactions may further be advanced from this entry, since the number of growing chains per neodymium atom exceeds three, and is close to the number of alkylmagnesium $[\mathrm{Mg}]-\mathrm{R}$ groups. A reversible transfer of a growing polystyrene chain between a lanthanide and a magnesium atom has been reported using chloroneodymocene [6] and cerium alkoxide [7] combined to dialkylmagnesium. The transmetallation between the lanthanide center and the magnesium that may occur here is described hereafter




where $\mathrm{X}$ represents a $\mathrm{BH}_{4}$ group and $\mathrm{PS} *$ a growing polystyrene chain.

We were further interested in the influence of the nature of the lanthanide atom on the course of the reaction. Using $\mathrm{La}\left(\mathrm{BH}_{4}\right)_{3}(\mathrm{THF})_{3}(2)$ and $\mathrm{Sm}\left(\mathrm{BH}_{4}\right)_{3}(\mathrm{THF})_{3}(3)$ as precatalysts shows that the activity of those catalytic systems is related to the nature of the rare earth (entries 1, 4 and 5). The lanthanum based catalytic system exhibits the highest activity after two hours reaction $(4900 \mathrm{~g} / \mathrm{mol} / \mathrm{h})$, neodymium a value of $3600 \mathrm{~g} / \mathrm{mol} / \mathrm{h}$ and samarium the lowest $(800 \mathrm{~g} / \mathrm{mol} / \mathrm{h})$. The initiation efficiency and/or the hypothetical transfer efficiency are in this latter case lower : the number-average molecular weight is consistent with the growth of 0.3 chains per magnesium atom. In opposition with the activity, the stereoselectivity of the reaction is not clearly related to the nature of the rare earth. The polystyrenes resulting from the precatalysts 1, 2, and 3 were all found to be quite atactic. Our interest is now focussed on the elucidation of the mechanism operating in the polymerisation of styrene by lanthanides borohydrides / alkylmagnesium systems.

\section{Experimental details}

\section{Materials}

All operations were performed under dry argon by using Schlenk techniques. Toluene ( $99.5 \%$ from Scharlau) was dried over sodium / benzophenone and distilled over molecular thieves before use. Styrene (99\% from Aldrich) was dried over calcium hydride, distilled twice over molecular thieves and once just before use. $n$-butylethylmagnesium $(20 \%$ wt. in heptane from Texas Alkyl) was used as received. The complexes $\left.\mathrm{Nd}\left(\mathrm{BH}_{4}\right)_{3}(\mathrm{THF})_{3} \quad \mathbf{1}, \mathrm{La}_{(\mathrm{BH}}\right)_{3}(\mathrm{THF})_{3} \quad 2$ and $\mathrm{Sm}\left(\mathrm{BH}_{4}\right)_{3}(\mathrm{THF})_{3} 3$ were synthesized according to literature procedures [8].

\section{Styrene polymerisation}

In a glove box, the borohydrido complex was weighted into a vessel. Toluene, $n$-butylethylmagnesium and styrene were added in the flask in this order using syringes. The mixture was magnetically stirred at the reaction temperature for a given time, diluted in toluene and the resulting solution was pourred into ethanol. Ethanol was evaporated under partial vacuum, and the product was dried under vacuum for $48 \mathrm{~h}$.

\section{Measurements}

The tacticity of the polymer was deduced from NMR data. ${ }^{1} \mathrm{H}$ and ${ }^{13} \mathrm{C}$ NMR spectra were recorded on a AC $400 \mathrm{Brücker}$ spectrometer at $400 \mathrm{~K}$ in tetrachloroethane- $d_{2}$, and the chemical shifts were calibrated using the residual resonances of the solvant. Size exclusion chromatography (SEC) was performed in THF as eluent at $20^{\circ} \mathrm{C}$ using a Waters SIS HPLC-pump, a Waters 410 refractometer and Waters styragel column (HR2, HR3, HR4, HR5E) calibrated with polystyrene standarts. 
Aknowledgments. The authors want to thank Catherine Méliet for NMR studies and Anne-Marie Cazé for SEC measurements.

\section{References}

[1] J.F. Pelletier, A. Mortreux, X. Olonde, K. Bujadoux, Angew. Chem. Int. Ed. Engl. 1996, 35, 1854

[2] J. Gromada, T. Chenal, A. Mortreux, J.W. Ziller, F. Leising, J.F. Carpentier, Chem. Commun. 2000, 2183

[3] M. Visseaux, T. Chenal, P. Roussel, A. Mortreux, J. Organomet. Chem. 2006, 691, 86

[4] F. Bonnet, M. Visseaux, A. Pereira, D. Baudry, Macromolecules 2005, 38, 3162

[5] P. Zinck, D. Baudry, A. Loupy, Macromol. Rapid Commun. 2005, 26, 46

[6] S. Bogaert, J.F. Carpentier, T. Chenal, A. Mortreux, G. Ricart, Macromol. Chem. Phys. 2000, 201, 1813

[7] Y. Sarazin, T. Chenal, A. Mortreux, H. Vezin, J.F. Carpentier, J. Mol. Catal. A 2005, 238, 207

[8] U. Mirsaidov, I.B. Shaimuradov, M. Khikmatov, Russ. J. Inorg. Chem 1986, 31, 753 
Table 1 Polymerisation of styrene with $\mathrm{Nd}\left(\mathrm{BH}_{4}\right)_{3}(\mathrm{THF})_{3}$ (1), $\mathrm{La}\left(\mathrm{BH}_{4}\right)_{3}(\mathrm{THF})_{3}$ (2), $\mathrm{Sm}\left(\mathrm{BH}_{4}\right)_{3}(\mathrm{THF})_{3}$ (3) and $n$ butylethylmagnesium - Selected entries

\begin{tabular}{llllllllll}
\hline Entry ${ }^{\text {a) }}$ & Complex & $\mathrm{St} / \mathrm{Nd}$ & $\mathrm{Mg} / \mathrm{Nd}$ & $\begin{array}{l}\text { Time } \\
(\mathrm{h})\end{array}$ & $\begin{array}{l}\text { Conversion } \\
(\%)\end{array}$ & $\begin{array}{l}\text { Activity } \\
(\mathrm{g} / \mathrm{mol} / \mathrm{h})\end{array}$ & $\begin{array}{l}\overline{\mathrm{M}_{\mathrm{n}}} \text { calc. }{ }^{\mathrm{b})} \\
(\mathrm{g} / \mathrm{mol})\end{array}$ & $\begin{array}{l}\left.\overline{\mathrm{M}}_{\mathrm{n}}{ }^{\mathrm{c}}\right) \\
(\mathrm{g} / \mathrm{mol})\end{array}$ & $\begin{array}{c}\text { PDI } \\
{ }^{\mathrm{d})}\end{array}$ \\
\hline 1 & $\mathbf{1}$ & 100 & 1 & 2 & 58 & 3600 & 3000 & 2700 & 1.7 \\
2 & $\mathbf{1}$ & 100 & 1 & 40 & 89 & $\mathrm{n} . \mathrm{d}$ & 4600 & 5100 & 2.2 \\
3 & $\mathbf{1}$ & 1000 & 10 & 20 & 32 & $\mathrm{n} . \mathrm{d}$ & 1700 & 2100 & 1.4 \\
4 & $\mathbf{2}$ & 100 & 1 & 2 & 78 & 4900 & 4100 & 6000 & 1.7 \\
5 & $\mathbf{3}$ & 100 & 1 & 2 & 12 & 800 & 620 & 4300 & 1.5
\end{tabular}

a) Reaction conducted at $50^{\circ} \mathrm{C}$ with $0.5 \mathrm{ml}$ styrene in $0.5 \mathrm{ml}$ toluene ${ }^{\text {b) }}$ Expected molecular weight assuming two growing chains per magnesium and taking the yield into account ${ }^{c}$ Number-average molecular weight measured by SEC ${ }^{\mathrm{d})}$ Polydispersity index measured by SEC 




Fig. 1 Apparent first-order kinetic plot of styrene polymerisation promoted by $\mathrm{Nd}\left(\mathrm{BH}_{4}\right)_{3}(\mathrm{THF})_{3} / n$-butylethylmagnesium. Experimental conditions : Styrene $/ \mathrm{Nd}=100, \mathrm{Mg} / \mathrm{Nd}=1,50^{\circ} \mathrm{C}$ in toluene 